\title{
Long noncoding RNA AFAP1-AS1 is upregulated in NSCLC and associated with lymph node metastasis and poor prognosis
}

\author{
XUECHUN LENG ${ }^{1 *}$, XIANGXIANG DING ${ }^{2 *}$, SIWEI WANG ${ }^{3 *}$, TIAN FANG $^{4}$, WENRONG SHEN $^{2}$, \\ WENJIA XIA ${ }^{3}$, RAN YOU ${ }^{4}$, KEPING XU ${ }^{1}$ and RONG YIN ${ }^{3}$ \\ ${ }^{1}$ Department of Thoracic Surgery, Huai'an First People's Hospital, Nanjing Medical University, \\ Huai'an, Jiangsu 223300; ${ }^{2}$ Department of Radiology, Cancer Institute of Jiangsu, Nanjing Medical University \\ Affiliated Cancer Hospital; ${ }^{3}$ Jiangsu Key Laboratory of Molecular and Translational Cancer Research, \\ Department of Radiology, Cancer Institute of Jiangsu, Nanjing Medical University Affiliated Cancer Hospital, \\ Nanjing, Jiangsu 210009; ${ }^{4}$ Department of Comparative Medicine, Jingling Hospital, \\ Nanjing University School of Medicine, Nanjing, Jiangsu 210002, P.R. China
}

Received November 30, 2016; Accepted January 12, 2018

DOI: $10.3892 / 01.2018 .8784$

\begin{abstract}
Long noncoding RNA (lncRNA) has been indicated to have an important role in various types of malignant tumors; however, only a small number of lncRNAs have been entirely elucidated. In the present study, a novel lncRNA, actin filament associated protein 1 antisense RNA 1 (AFAP1-AS1), was investigated, which is highly expressed in non-small cell lung cancer (NSCLC). Reverse transcription-quantitative polymerase chain reaction and in situ hybridization were performed to detect AFAP1-AS1 expression in frozen tissues and tissue microarrays, respectively. The results revealed that the expression level of AFAP1-AS1 was significantly increased in tumor tissues, compared with the paired non-cancerous tissues. It was also determined that the AFAP1-AS1 expression level was higher in patients with lymph node metastasis than those without lymph node metastasis $(\mathrm{P}=0.014)$. Kaplan-Meier analysis was conducted to evaluate the overall survival of patients with NSCLC and different expression levels of AFAP1-AS1, and the results indicated that patients with high AFAP1-AS1 expression had a reduced survival time, compared with those with low AFAP1-AS1 expression $(\mathrm{P}=0.011)$. Cox regression analysis was also performed to analyze the prognostic value of lncRNA AFAP1-AS1. The obtained data demonstrated that IncRNA AFAP1-AS1 was an unfavorable prognostic biomarker for NSCLC (HR: 3.12, 95\% CI (1.05-9.25), P=0.040). In
\end{abstract}

Correspondence to: Professor Keping Xu, Department of Thoracic Surgery, Huai'an First People's Hospital, Nanjing Medical University, 6 West Beijing Road, Huai'an, Jiangsu 223300, P.R. China

E-mail: keping_xu@163.com

*Contributed equally

Key words: long noncoding RNA, non-small cell lung cancer, prognosis conclusion, it was demonstrated that lncRNA AFAP1-AS1 is overexpressed in NSCLC and an unfavorable biomarker for patients with NSCLC.

\section{Introduction}

According to the cancer statistics for 2016, lung cancer was the leading cause of cancer-associated mortality in China (1). In addition, it is difficult to diagnose patients with lung cancer at a very early stage, and tumor biomarkers for early diagnosis and metastasis identification are lacking (2). Despite the improvement of treatments, the prognosis of non-small cell lung cancer (NSCLC) is still poor and the 5-year survival rate is only $11-15 \%(3,4)$.

Previous studies have confirmed the importance of non-protein coding genes in carcinogenesis and metastasis $(5,6)$. Among those non-proteins coding RNAs, long noncoding RNAs (lncRNAs) have participated in a great extent of cancer biological processes (6-8). IncRNA is a type of RNA without the ability of encoding protein and $>200$ nucleotides in length $(9,10)$. According to the existing research results, the dysregulation of lncRNA serves a critical role in human cancers $(5,10,11)$. In lung cancer, a number of cancer-associated lncRNAs have been demonstrated to be biomarkers for metastasis or prognosis, including HOX transcript antisense RNA (HOTAIR) $(12,13)$, metastasis associated long antisense transcript 1 (MALAT1) $(14,15)$ and colon cancer-associated transcript 2 (16).

To identify functional lncRNAs, microarrays have been frequently utilized to investigate lncRNA expression in tumor tissues (17). In a previous study, it was indicated that a lncRNA termed as actin filament associated protein 1 antisense RNA 1 (AFAP1-AS1) was significantly overexpressed in lung cancer, as demonstrated by microarrays (17). Evidence has indicated that AFAP1-AS1 is associated with tumor cell migration and invasion $(18,19)$. However, the prognostic role of AFAP1-AS1 has not been fully explored in NSCLC (20). Therefore, the AFAP1-AS1 expression level was analyzed by reverse transcription-quantitative polymerase chain reaction (RT-qPCR) 
and in situ hybridization (ISH), and the prognostic value of AFAPA-AS1 was investigated.

\section{Materials and methods}

Patients and tissue samples. The study was approved by the Ethics Boards of the Cancer Institute of Jiangsu (Nanjing, China). The characteristics of analyzed patients are presented in Tables I and II. Lung cancer tissues and adjacent normal tissues were obtained from patients that received surgical resection of lung cancer from January 2012 to December 2015 at the Department of Thoracic Surgery, Cancer Institute of Jiangsu. A tissue microarray (TMA) cohort of 74 patients (55 males and 19 females), with a median age of 61.1 years, and a PCR cohort of 52 patients with NSCLC (30 males and 22 females), with a median age of 59.0 years, were included in the present study. The TMA cohort data was generated in 2015 and the PCR cohort data in 2016. The patient samples were obtained from the Cancer Institute of Jiangsu. All patients diagnosed with NSCLC who had never received any therapy prior to surgery were collected. Clinical data including age, sex, smoking history, stage, lymph node metastasis of these patients were collected from all patients. In addition, informed written consents were obtained from all patients included in the present study.

$R N A$ extraction and RT-qPCR. Total RNA was extracted from tissue samples with TRIzol ${ }^{\circledR}$ (Invitrogen; Thermo Fisher Scientific, Inc., Waltham, MA, USA), following the manufacturer's protocol. PrimerScript RT Master Mix (Takara Biotechnology Co., Ltd., Dalian, China) was used to reverse transcribe RNA into a final volume of $20 \mu l$. Then, RT-qPCR was executed using the SYBR ${ }^{\circledR}$ Select Master Mix (Applied Biosystems; Thermo Fisher Scientific, Inc.; cat. no. 4472908) with $0.5 \mu \mathrm{l}$ cDNA on the QuantStudio ${ }^{\mathrm{TM}} 6$ flex system (Applied Biosystems; Thermo Fisher Scientific, Inc.), according to the manufacturer's instructions. GAPDH were used as internal controls. The primers sequence are as follows: Forward, 5'-TCGCTCAATGGAGTGACGGCA-3' and reverse, 5'-CGG CTGAGACCGCTGAGAACTT-3' for AFAP1-AS1; forward, 5'-CCACATCGCTCAGACACCAT-3' and reverse, 5'-ACC AGGCGCCCAATACG-3' for GAPDH. The RT-qPCR reaction was implemented with the following conditions: $95^{\circ} \mathrm{C}$ for $10 \mathrm{~min}, 40$ cycles of $95^{\circ} \mathrm{C}$ for $15 \mathrm{sec}$ and $60^{\circ} \mathrm{C}$ for $1 \mathrm{~min}$. The expression fold changes were calculated by $2^{-\Delta \Delta \mathrm{Cq}}$ methods $(21,22)$. Every sample was performed in triplicate.

TMA and ISH analysis. TMAs included samples fixed with $10 \%$ formalin at room temperature for $24-48 \mathrm{~h}$ and embedded in paraffin from 82 pairs of NSCLC tissue and adjacent normal lung tissues, and were constructed by Shanghai Biochip Co., Ltd (Shanghai, China). After processing, unspotted slides from the TMA block were used for the ISH with probes for AFAP1-AS1 (Exiqon A/S, Vedbaek, Denmark). The TMA was placed in an oven at $60^{\circ} \mathrm{C}$ for $1 \mathrm{~h}$ then stored overnight at $4^{\circ} \mathrm{C}$. Following that, slides were washed with xylene at $18^{\circ} \mathrm{C}$ and rehydrated with $100 \%$ ethanol solutions at room temperature and then incubated with Proteinase-K (Nanjing KeyGen Co., Ltd., Nanjing China) for $7.5 \mathrm{~min}$ at $37^{\circ} \mathrm{C}$. Additionally, $1,000 \mathrm{nmol} / \mathrm{l}$ AFAP1-AS1 probe (Shanghai Bogoo Biological

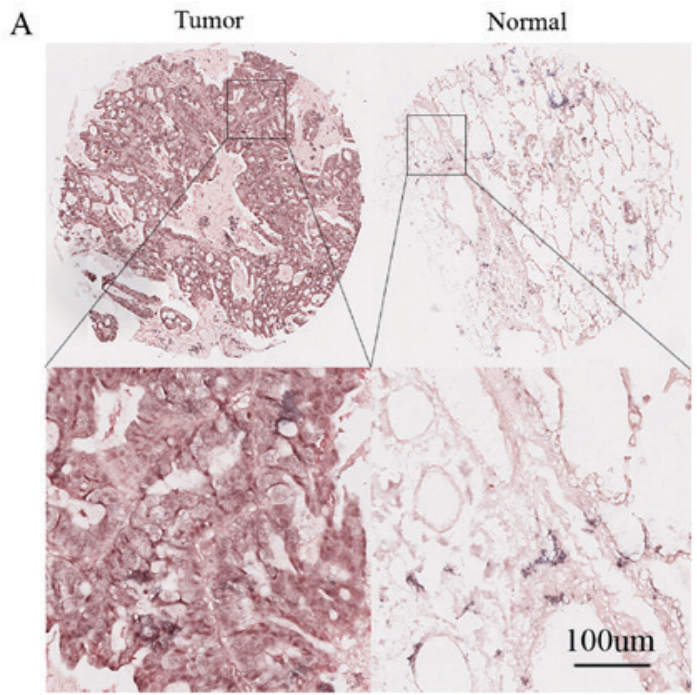

B

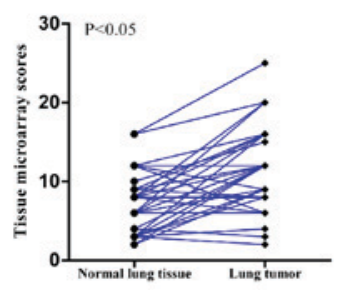

C

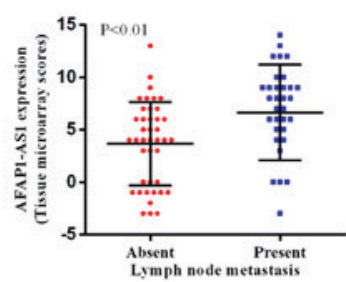

Figure 1. AFAP1-AS1 is highly expressed in lung cancer as shown by tissue microarray. (A) AFAP1-AS1 expression level of tumor is significantly higher than that of normal lung tissues in the tissue microarray according to the magnified images. (B) Staining scores of AFAP1-AS1 in lung cancer and normal tissues. (C) Patients with positive lymph nodes were significantly more likely to indicate overexpression of AFAP1-AS1, compared with patients with no lymph node spread, which was indicated by the microarray scores. AFAP1-AS1, actin filament associated protein 1 antisense RNA 1.

Technology Co., Ltd. Shanghai China) was used to hybridize slides in a SSC buffer $(150 \mathrm{mM}$ sodium chloride and $15 \mathrm{mM}$ trisodium citrate) for $20 \mathrm{~min}$ at $50^{\circ} \mathrm{C}$. Afterwards, the slides were washed with SSC buffers $(150 \mathrm{mM}$ sodium chloride and $15 \mathrm{mM}$ trisodium citrate). Following this, the slides were stained with 3,3'-diaminobenzidine horseradish peroxidase chromogenic liquid (Shanghai Bogoo Biological Technology Co., Ltd.) at room temperature for $15 \mathrm{~min}$. Following washing, slides were ready for imaging. Visible colonies were counted using light microscopy and a fluorescence microscope at magnification, $\mathrm{x} 40$. The software used for analysis was Aperio ImageScope v11.1.2.752. (Leica Microsystems $\mathrm{GmbH}$, Wetzlar, Germany). Following this, the slides were scored comprehensively according to size and intensity of the staining, as reported previously $(23,24)$. Size: $<10 \%, 1$ point; $\geq 10 \%-<30 \%, 2$ points; $\geq 30 \%-<50 \%, 3$ points; $\geq 50 \%-<75 \%$, 4 points; $\geq 75 \%, 5$ points. Intensity: Soft red, 1 point; sandy beige, 2 points; claybank, 3 points; brown, 4 points; sepia, 5 points. The intensities were multiplied by the sizes and the scores were calculated by taking the normal lung tissue's score away from the NSCLC tissues' score. According to the final scores, the ASAP1-AS1 expression level was divided into high (score $\geq 1$ ) and low (score $<1$ ). The evaluation was completed by two pathologists blinded to the patient's outcome and clinical characteristics. 
Table I. Association between lncRNA AFAP1-AS1 expression levels to clinical, biological and histo-morphological factors in the tissue microarray cohort.

AFAP1-AS1 expression level

\begin{tabular}{|c|c|c|c|c|}
\hline & & & & \\
\hline Factor & Number of patients & Low & High & P-value \\
\hline Sex & & & & 0.140 \\
\hline Male & 55 & 11 & 44 & \\
\hline Female & 19 & 7 & 12 & \\
\hline Age, years & & & & 0.988 \\
\hline$\leq 60$ & 33 & 8 & 25 & \\
\hline$>60$ & 41 & 10 & 31 & \\
\hline Smoking status & & & & 0.136 \\
\hline Yes & 44 & 8 & 36 & \\
\hline No & 30 & 10 & 20 & \\
\hline Histology & & & & 0.981 \\
\hline $\mathrm{SCC}$ & 17 & 4 & 13 & \\
\hline $\mathrm{AC}$ & 48 & 12 & 36 & \\
\hline Others & 9 & 2 & 7 & \\
\hline Tissue differentiation & & & & 0.420 \\
\hline Middle and high & 27 & 8 & 19 & \\
\hline Low & 47 & 10 & 37 & \\
\hline Stage & & & & 0.423 \\
\hline IA, IB, IIA and IIB & 52 & 14 & 38 & \\
\hline IIIA, IIIB and IV & 22 & 4 & 18 & \\
\hline Lymph node metastasis & & & & P.007 \\
\hline Present & & & & \\
\hline Absent & & & & \\
\hline
\end{tabular}

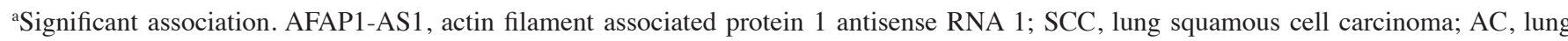
adenocarcinoma.

Statistical analysis. Data analysis was performed with SPSS 20.0 software (IBM Corp., Armonk, NY, USA). Paired Student's t-test, one-way analysis of variance (Bonferroni post-hoc test) and Spearman's rank test were applied to analyze the association between AFAFP1-AS1 expression and clinical characteristics. The variables associated with the prognostic values were tested with overall survival time as the endpoint in the univariate and multivariate analysis, which was conducted by Cox regression analysis. The hazard ratio (HR) and its 95\% confidence interval (CI) were derived from these results. GraphPad (GraphPad Software, Inc., La Jolla, CA, USA) was used to produce the Kaplan-Meier survival curve. Data are presented as the mean \pm standard error of the mean. $\mathrm{P}<0.05$ was considered to indicate a statistically significant difference.

\section{Results}

AFAP1-AS1 is overexpressed in NSCLC tumor tissues and correlates with clinical characteristics. Firstly, the AFAP1-AS1 expression level was analyzed via ISH in NSCLC tumor tissues. Subsequent to excluding 8 pairs for missing data (4 tumor tissues and 4 normal tissues), the expression of AFAP1-AS1 was compared between tumor tissues and normal tissues. As indicated, AFAP1-AS1 was significantly overexpressed in 56 lung tumor tissues, compared with paired adjacent normal lung tissues $(\mathrm{P}<0.001$; Fig. $1 \mathrm{~A}$ and $\mathrm{B})$. There was a positive correlation between AFAP1-AS1 expression and lymph node metastasis ( $\mathrm{P}=0.007$; Table I; Fig. 1C). However, there were no associations between AFAP1-AS1 expression and age, sex, smoking, histology or stage.

Following this, RT-qPCR was also performed in an independent cohort of 52 patients with NSCLC. AFAP1-AS1 was overexpressed in $77.0 \%$ (40/52) of patients with NSCLC, with mean upregulation of 8.65 -fold ( $\mathrm{P}=0.040$; Fig. 2A). Additionally, overexpression of AFAP1-AS1 was positively correlated with tissue differentiation $(\mathrm{P}=0.041$; Table II) and lymph node metastasis ( $\mathrm{P}=0.014$; Table II; Fig. 2B).

Prognostic value of AFAP1-AS1 lncRNA expression in patients with lung cancer. Kaplan-Meier survival analysis demonstrated that patients with low expression level of AFAP1-AS1 had an improved survival time ( $\mathrm{P}=0.011$; Fig. 3). To additionally explore the association between IncRNA AFAP1-AS1 and prognosis, Cox regression analysis was 
Table II. Correlation of lncRNA AFAP1-AS1 expression levels to clinicopathological characteristic in the polymerase chain reaction cohort.

\begin{tabular}{|c|c|c|c|}
\hline Characteristics of all patients in this cohort & Number of patients & AFAP1-AS1 level (fold change) & P-value \\
\hline \multicolumn{4}{|l|}{ Age, years } \\
\hline$\leq 60$ & 27 & 11.28 & \\
\hline$>60$ & 25 & 10.58 & 0.062 \\
\hline \multicolumn{4}{|l|}{ Sex } \\
\hline Male & 30 & 9.56 & \\
\hline Female & 22 & 8.33 & 0.928 \\
\hline \multicolumn{4}{|l|}{ Smoking } \\
\hline No & 38 & 9.93 & \\
\hline Yes & 14 & 6.63 & 0.074 \\
\hline \multicolumn{4}{|l|}{ Tumor size, $\mathrm{cm}$} \\
\hline $1.0 \times 1.0-3.0 \times 4.0$ & 35 & 10.44 & \\
\hline $3.0 \times 4.0-8.0 \times 5.0$ & 17 & 6.16 & 0.071 \\
\hline \multicolumn{4}{|l|}{ Histology } \\
\hline SCC & 7 & 8.61 & \\
\hline $\mathrm{AC}$ & 45 & 9.11 & 0.771 \\
\hline \multicolumn{4}{|l|}{ Tissue differentiation } \\
\hline Middle and high & 28 & 8.81 & \\
\hline Low & 24 & 7.64 & $0.041^{\mathrm{a}}$ \\
\hline \multicolumn{4}{|l|}{ Lymph node metastasis } \\
\hline Absent & 33 & 5.89 & \\
\hline Present & 19 & 14.52 & $0.014^{\mathrm{a}}$ \\
\hline \multicolumn{4}{|l|}{ Stage } \\
\hline IA, IB, IIA and IIB & 36 & 11.1 & \\
\hline IIIA, IIIB and IV & 16 & 4.4 & 0.064 \\
\hline
\end{tabular}

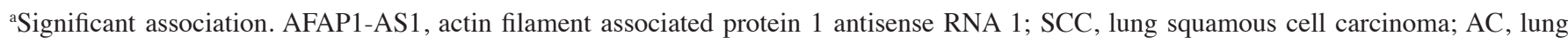
adenocarcinoma.

conducted. Kaplan-Meier analysis showed that the high expression level of AFAP1-AS1 was significantly associated with poor overall survival time (HR, 3.58; 95\% CI, 1.25-10.24; $\mathrm{P}=0.0113$; Table III). Subsequently, AFAP1-AS1 was separately introduced to the base multivariate model including age, sex, smoking, tissue differentiation, stage and lymph node metastasis. High expression level of ASAP1-S1 was an independent prognostic factor of poor survival time for lung cancer (HR, 3.12; 95\% CI, 1.05-9.25; P=0.040; Table III).

\section{Discussion}

Recently, a number of studies have demonstrated that lncRNAs serve an important role in cancer pathogenesis $(20,25)$. Additionally, the association between lncRNA and tumor development and progression have been demonstrated $(26,27)$. In addition, IncRNA has been indicated to be a novel biomarker for cancer diagnosis, prognosis and metastasis, and therefore have a therapeutic effect (6).

Notably, associations between lncRNAs, including HOTAIR and MALAT1, and human cancers have been previously reported (28). Upregulation of HOTAIR in lung tumor tissues is associated with metastasis, drug resistance and poor survival time in patients with lung cancer (29). Furthermore, HOTAIR has been indicated as a biomarker in lung cancer $(12,13,30)$. Additionally, high-expression of MALAT1 in primary tumors is a biomarker of metastasis and poor survival time $(14,15,31)$.

As indicated by the microarray data, AFAP1-AS1 was upregulated in lung cancer tissues, compared with relative normal tissues. In the present study, ISH and RT-qPCR was conducted to analyze the expression of AFAP1-AS1 in lung cancer tissues. Following this, the association between AFAP1-AS1 expression level and clinical characteristics was investigated. Statistical analysis revealed that the overexpression of AFAP1-AS1 was associated with lymph node metastasis. Furthermore, the high expression level of ASAP1-S1 also indicated poor survival time in patients with NSCLC.

The present study indicated that the overexpression of AFAP1-AS1 was notably associated with the poor survival time in patients with NSCLC. However, the precise mechanism underlying this effect remains unknown. Further experimental evidence is required to explore the mechanism underlying AFAP1-AS1 leading to poor outcomes. 
Table III. AFAP1-AS1 expression levels in Cox univariate and multivariate analysis for overall survival.

\begin{tabular}{|c|c|c|c|c|c|c|c|}
\hline \multirow[b]{2}{*}{ Factor } & \multirow[b]{2}{*}{ Number of patients } & \multicolumn{3}{|c|}{ Univariate analysis } & \multicolumn{3}{|c|}{ Multivariate analysis } \\
\hline & & HR & $95 \% \mathrm{CI}$ & P-value & HR & $95 \% \mathrm{CI}$ & P-value \\
\hline \multicolumn{8}{|l|}{ Sex } \\
\hline Male & 55 & 1 & & & 1 & & \\
\hline Female & 19 & 0.61 & $0.26-1.40$ & 0.238 & 0.82 & $0.26-2.62$ & 0.740 \\
\hline \multicolumn{8}{|l|}{ Age, years } \\
\hline$\leq 60$ & 33 & 1 & & & 1 & & \\
\hline$>60$ & 41 & 1.18 & $0.60-2.31$ & 0.629 & 1.29 & $0.62-2.69$ & 0.499 \\
\hline \multicolumn{8}{|l|}{ Smoking } \\
\hline No & 30 & 1 & & & 1 & & \\
\hline Yes & 44 & 1.11 & $0.56-2.20$ & 0.758 & 1.10 & $0.42-2.87$ & 0.839 \\
\hline \multicolumn{8}{|l|}{ Tissue differentiation } \\
\hline Middle and high & 27 & 1 & & & 1 & & \\
\hline Low & 47 & 0.82 & $0.42-1.61$ & 0.565 & 0.49 & $0.23-1.05$ & 0.065 \\
\hline \multicolumn{8}{|l|}{ Stage } \\
\hline IA, IB, IIA and IIB & 52 & 1 & & & 1 & & \\
\hline IIIA, IIIB and IV & 22 & 1.41 & $0.70-2.84$ & 0.333 & 0.68 & $0.26-1.73$ & 0.416 \\
\hline \multicolumn{8}{|c|}{ Lymph node metastasis } \\
\hline Absent & 33 & 1 & & & 1 & & \\
\hline Present & 41 & 2.33 & $1.19-4.56$ & $0.014^{\mathrm{a}}$ & 3.54 & $1.36-9.22$ & $0.009^{\mathrm{a}}$ \\
\hline \multicolumn{8}{|c|}{ AFAP1-AS1 expression } \\
\hline Low & 18 & 1 & & & 1 & & \\
\hline High & 56 & 3.58 & $1.25-10.24$ & $0.017^{\mathrm{a}}$ & 3.12 & $1.05-9.25$ & $0.040^{\mathrm{a}}$ \\
\hline
\end{tabular}

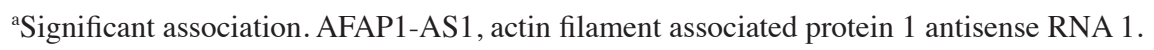
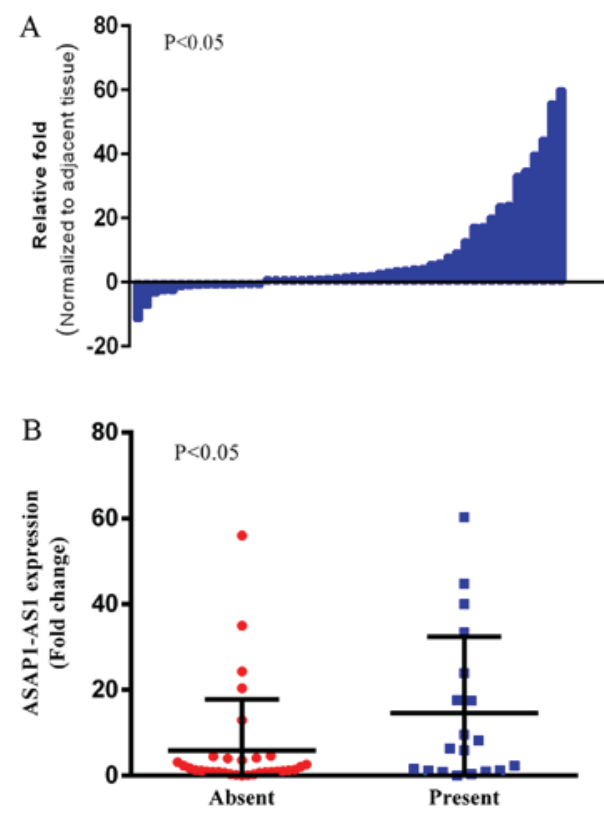

Lymph node metastasis

Figure 2. AFAP1-AS1 is overexpressed in lung cancer showed by reverse transcription-quantitative polymerase chain reaction. (A) AFAP1-AS1 is overexpressed in (40/52) lung cancer tissues, with mean overexpression of 8.65-fold, as compared with paired normal tissues. (B) Patients with positive lymph nodes had a significantly increased expression of AFAP1-AS1, compared with patients with no lymph node spread. AFAP1-AS1, actin filament associated protein 1 antisense RNA 1.

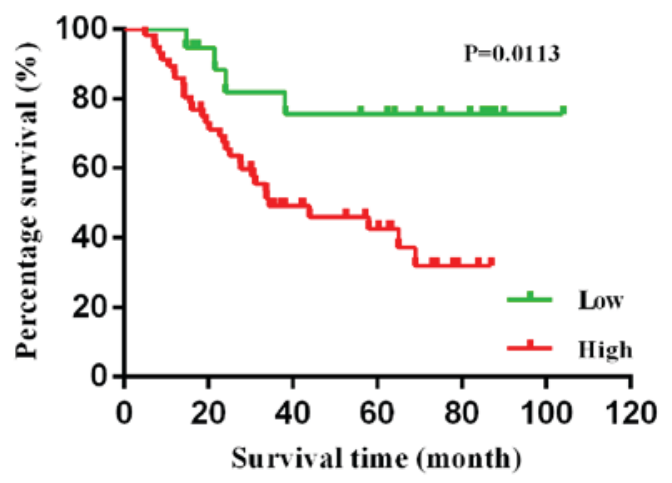

Figure 3. High expression of AFAP1-AS1 is associated with poorer prognosis of lung cancer (HR, 3.58; 95\% CI, 1.25-10.24; $\mathrm{P}=0.0113$ ). AFAP1-AS1, actin filament associated protein 1 antisense RNA 1.

To conclude, it was demonstrated that the expression level of AFAP1-AS1 is upregulated in NSCLC and correlates with lymph node metastasis. High AFAP1-AS1 expression level indicated a poor prognosis for the patient with lung cancer. Therefore, AFAP1-AS1 could be a potential biomarker for predicting NSCLC progression and prognosis.

\section{Acknowledgements}

Not applicable. 


\section{Funding}

The present study was supported by the Technology Projects of Jiangsu Provincial Commission of Health and Family Planning (grant no. H201457), the Natural Science Foundation of China (grant nos. 81201830 and 81472200 to Rong Yin), Natural Science Foundation for High Education of Jiangsu (grant no. 13KJB320010 to Rong Yin) and Jiangsu Ordinary University Graduate Student Research Innovation Project for 2013 (grant no. CXLX13_571 to Mantang Qiu).

\section{Availability of data and materials}

The data generated during the present study is available upon reasonable request from the corresponding author.

\section{Authors' contributions}

$\mathrm{XL}, \mathrm{XD}$ and $\mathrm{KX}$ conceived the study. XL and XD designed the study. TF, WS and RY coordinated the study. XL, XD and SW performed the majority of the experiments and statistical analyses. WS and TF obtained the clinical data. XL and RY drafted the manuscript. KX and RY provided funds. WS, TF and WX revised the manuscript and obtained the clinical data. All authors read and approved the final manuscript.

\section{Ethics approval and consent to participate}

This study was approved by the Ethics Boards of the Cancer Institute of Jiangsu Province. Informed written consent was obtained from all patients included in this research.

\section{Consent for publication}

All patients provided written informed consent for the publication of their data.

\section{Competing interests}

The authors declare that they have no competing interests.

\section{References}

1. Chen W, Zheng R, Baade PD, Zhang S, Zeng H, Bray F, Jemal A, Yu XQ and He J: Cancer statistics in China, 2015. CA Cancer J Clin 66: 115-32, 2016.

2. Aggarwal C: Targeted therapy for lung cancer: Present and future. Ann Palliat Med 3: 229-235, 2014.

3. Raungrut P, Wongkotsila A, Lirdprapamongkol K, Svasti J, Geater SL, Phukaoloun M, Suwiwat S and Thongsuksai P: Prognostic significance of 14-3-3 $\gamma$ overexpression in advanced non-small cell lung cancer. Asian Pac J Cancer Prev 15: 3513-3518, 2014.

4. Youlden DR, Cramb SM and Baade PD: The International Epidemiology of lung cancer: Geographical distribution and secular trends. J Thorac Oncol 3: 819-831, 2008.

5. Schmitt AM and Chang HY: Long noncoding RNAs in cancer pathways. Cancer Cell 29: 452-463, 2016.

6. Qiu MT, HU JW, Yin R and Xu L: Long noncoding RNA: An emerging paradigm of cancer research. Tumour Biol 34: 613-620, 2013.

7. Gupta RA, Shah N, Wang KC, Kim J, Horlings HM, Wong DJ, Tsai MC, Hung T, Argani P, Rinn JL, et al: Long non-coding RNA HOTAIR reprograms chromatin state to promote cancer metastasis. Nature 464: 1071-1076, 2010.

8. Esteller M: Non-coding RNAs in human disease. Nat Rev Genet 12: 861-874, 2011.
9. Mercer TR, Dinger ME and Mattick JS: Long non-coding RNAs: insights into functions. Nat Rev Genet 10: 155-159, 2009.

10. Ponting CP, Oliver PL and Reik W: Evolution and functions of long noncoding RNAs. Cell 136: 629-641, 2009.

11. Zaratiegui M, Irvine DV and Martienssen RA: Noncoding RNAs and gene silencing. Cell 128: 763-776, 2007.

12. Ono H,Motoi N, Nagano H,Miyauchi E, Ushijima M, Matsuura M, Okumura S, Nishio M, Hirose T, Inase N and Ishikawa Y: Long noncoding RNA HOTAIR is relevant to cellular proliferation, invasiveness, and clinical relapse in small-cell lung cancer. Cancer Med 3: 632-642, 2014.

13. Zhao W, An Y, Liang Y and Xie XW: Role of HOTAIR long noncoding RNA in metastatic progression of lung cancer. Eur Rev Med Pharmacol Sci 18: 1930-1936, 2014.

14. Jeffers LK, Duan K, Ellies LG, Seaman WT, Burger-Calderon RA, Diatchenko LB and Webster-Cyriaque J: Correlation of transcription of MALAT-1, a novel noncoding RNA, with deregulated expression of tumor suppressor p53 in small DNA tumor virus models. J Cancer Ther 4, 2013.

15. Ji P, Diederichs S, Wang W, Böing S, Metzger R, Schneider PM, Tidow N, Brandt B, Buerger H, Bulk E, et al: MALAT-1, a novel noncoding RNA, and thymosin beta4 predict metastasis and survival in early-stage non-small cell lung cancer. Oncogene 22: 8031-8041, 2003.

16. Qiu M, Xu Y, Yang X, Wang J, Hu J, Xu L and Yin R: CCAT2 is a lung adenocarcinoma-specific long non-coding RNA and promotes invasion of non-small cell lung cancer. Tumour Biol 35: 5375-5380, 2014.

17. Qiu M, Xu Y, Wang J, Zhang E, Sun M, Zheng Y, Li M, Xia W, Feng D, Yin R and Xu L: A novel lncRNA, LUADT1, promotes lung adenocarcinoma proliferation via the epigenetic suppression of p27. Cell Death Dis 6: e1858, 2015.

18. Deng J, Liang Y, Liu C, He S and Wang S: The up-regulation of long non-coding RNA AFAP1-AS1 is associated with the poor prognosis of NSCLC patients. Biomed Pharmacother 75: 8-11, 2015.

19. Zeng Z, Bo H, Gong Z, et al: AFAP1-AS1, a long noncoding RNA upregulated in lung cancer and promotes invasion and metastasis. Tumour Biol 37: 729-737, 2016.

20. Zhang F, Li J, Xiao H, Zou Y, Liu Y and Huang W: AFAP1-AS1: A novel oncogenic long non-coding RNA in human cancers. Cell Prolif 51: 12397, 2018.

21. Livak KJ and Schmittgen TD: Analysis of relative gene expression data using real-time quantitative PCR and the 2(-Delta Delta C(T)) method. Methods 25: 402-408, 2001.

22. VanGuilder HD, Vrana KE and Freeman WM: Twenty-five years of quantitative PCR for gene expression analysis. Biotechniques 44: 619-626, 2008.

23. Krajewska M, Krajewski S, Epstein JI, Shabaik A, Sauvageot J, Song K, Kitada S and Reed JC: Immunohistochemical analysis of bcl-2, bax, bcl-X, and mcl-1 expression in prostate cancers. Am J Pathol 148: 1567-1576, 1996.

24. Ding Y, Shimada Y, Maeda M, Kawabe A, Kaganoi J, Komoto I, Hashimoto Y, Miyake M, Hashida H and Imamura M: Association of CC chemokine receptor 7 with lymph node metastasis of esophageal squamous cell carcinoma. Clin Cancer Res 9: 3406-3412, 2003.

25. Wang ZY, Hu M, Dai MH, Xiong J, Zhang S, Wu HJ, Zhang SS and Gong ZJ: Upregulation of the long non-coding RNA AFAP1-AS1 affects the proliferation, invasion and survival of tongue squamous cell carcinoma via the $\mathrm{Wnt} / \beta$-catenin signaling pathway. Mol Cancer 17: 3, 2018.

26. Negishi M, Wongpalee SP, Sarkar S, et al: A new lncRNA, APTR, associates with and represses the CDKN1A/p21 promoter by recruiting polycomb proteins. PLoS One 9: e95216, 2014.

27. Yang X, Gao L, Guo X, Shi X, Wu H, Song F and Wang B: A network-based method for analysis of IncRNA-disease associations and prediction of 1 ncRNAs implicated in diseases. PLoS One 9: e87797, 2014.

28. Sun W, Yang Y, Xu C and Guo J: Regulatory mechanisms of long noncoding RNAs on gene expression in cancers. Cancer Genet 216-217: 105-110, 2017.

29. Yu X and Li Z: Long non-coding RNA HOTAIR: A novel oncogene (Review). Mol Med Rep 12: 5611-5618, 2015.

30. Loewen G, Jayawickramarajah J, Zhuo Y and Shan B: Functions of lncRNA HOTAIR in lung cancer. J Hematol Oncol 7: 90, 2014.

31. Zhang HM, Yang FQ, Chen SJ, Che J and Zheng JH: Upregulation of long non-coding RNA MALAT1 correlates with tumor progression and poor prognosis in clear cell renal cell carcinoma. Tumour Biol 36: 2947-2955, 2015.

This work is licensed under a Creative Commons Attribution-NonCommercial-NoDerivatives 4.0 International (CC BY-NC-ND 4.0) License. 